\title{
ENRAIZAMENTO DE ESTACAS DE MARACUJAZEIRO CULTIVADAS EM DIFERENTES SUBSTRATOS E TRATADAS COM EXTRATOS DE TIRIRICA
}

PEREIRA, Eldelon de Oliveira ${ }^{1}$ LOPES, José Carlos ${ }^{2}$ MARÇAL, Tiago de Souza ${ }^{3}$ COELHO, Ruimário Inácio ${ }^{4}$

RESUMO: Este trabalho objetivou avaliar o efeito de extratos hidroalcóolicos de tiririca (Cyperus rotundus L.) na rizogênese de estacas de maracujazeiro amarelo (Passiflora edulis Sims f. flavicarpa) cultivadas em dois substratos, $\mathrm{S}_{1}$ : substrato comercial e $\mathrm{S}_{2}$ : vermiculita expandida. $\mathrm{O}$ estudo foi realizado em estufa com $50 \%$ de sombreamento e nebulização intermitente no Centro de Ciências Agrárias da Universidade Federal do Espírito Santo State, AlegreES. Os extratos de tubérculos e bulbos basais de C. rotundus foram preparados nas concentrações de $50 \%, 75 \%$ e $100 \%$ e testemunha (água deionizada). Os parâmetros avaliados foram: porcentagem de enraizamento (PE); número de raízes (NR); comprimento da maior raiz (CR), massa fresca (MF) e seca das raízes (MS). Não foi observado efeito significativo da interação substrato x extrato para nenhuma variável. A porcentagem de enraizamento não diferiu significativamente entre os substratos, sendo que as médias foram de 94,05 e 89,28\% para $\mathrm{S}_{1}$ e $\mathrm{S}_{2}$, respectivamente. Contudo, para MF, MS e CR o $S_{1}$ apresentou médias superiores e que diferiram significativamente de $S_{2}$, favorecendo o desenvolvimento radicular das estacas. As concentrações do extrato hidroalcóolico de bulbo basal e tubérculo de $C$. rotundus testadas não influenciam o enraizamento de estacas de maracujazeiro amarelo.

Palavras-chave: Fitormônio. Propagação. Cyperaceae.

\section{ROOTING OF PASSION FRUIT CUTTING GROWN IN DIFFERENT SUBSTRATES AND TREATED WITH EXTRACTS NUTSEDGE}

SUMMARY: This study evaluated the effect of hydroalcoholic extract of purple nutsedge (Cyperus rotundus L.) in rooting cuttings of yellow passionfruit (Passiflora edulis Sims f. flavicarpa) grown in two substrates, $\mathrm{S}_{1}$ : commercial substrate and $\mathrm{S}_{2}$ : expanded vermiculite. The trial was conducted in greenhouse with $50 \%$ shading and intermittent nebulization at the Centro de Ciências Agrárias da Universidade Federal do Espírito Santo (CCA-UFES), Alegre-ES. The extracts of tubers and basal bulbs of C. rotundus were made in concentrations of 50\%, 75\% and 100\% and control (deionized water). The parameters evaluated were: percentage of rooting (PE), number of roots (NR), length of roots (CR), fresh weight (MF) and dry weight of roots (MS). There was no significant effect of substrate $\mathrm{x}$ extract interaction for any variable. The rooting percentage did not differ significantly between the substrates, and the averages were 94.05 and $89.28 \%$ for $S_{1}$ and $S_{2}$, respectively. However, for MF, MS and CR the $S_{1}$ showed greater means and that differed significantly of $S_{2}$, favoring the root development of cuttings. The concentrations of the hydroalcoholic extracts of basal bulb and tuber of C. rotundus tested do not influence the rooting of passion fruit.

Keywords: Phytohormone. Propagation. Cyperaceae.

\section{INTRODUÇÃO}

O maracujazeiro (Passiflora spp.) é originário da América Tropical, compreendendo 150 espécies

\footnotetext{
${ }^{1}$ Mestrando em Fitotecnia no Programa de Pós-graduação em Produção Vegetal no Centro de Ciências Agrárias da Universidade Federal do Espírito Santo (PPGPV-CCA/UFES). e-mail: eldelon_01@ yahoo.com.br

2, ${ }^{4}$ Departamento de Produção Vegetal (PPGPV-CCA-UFES). CP.: 16, CEP: 29500-000, Alegre - ES. e-mail: jcufes@bol.com.br; ruimario@cca.ufes.br

${ }^{3}$ Graduando do curso de Agronomia do Centro de Ciências Agrárias da Universidade Fed. do Esp. Sto (CCA-UFES)
} 
da família Passifloraceae utilizadas para consumo humano (RONCATTO et al., 2008a). O maracujazeiro amarelo (Passiflora edulis Sims f. flavicarpa), também conhecido como maracujazeiro azedo, é a espécie mais cultivada no Brasil e seus frutos são destinados tanto para o consumo in natura quanto para fins de industrialização, abastecendo o mercado interno (SILVA et al., 2005; RONCATTO et al., 2008b). A produção nacional no ano de 2009 foi de 713.515 toneladas em uma área de 50.795 hectares. $\mathrm{O}$ estado da Bahia é o maior produtor, com 317.475 toneladas em uma área de 23.227 hectares, seguido pelos estados do Rio Grande do Norte, Sergipe, Espírito Santo e Minas Gerais (IBGE, 2009).

A propagação do maracujazeiro pode ser realizada via sementes, bem como por estaquia e enxertia (NOGUEIRA FILHO et al., 2011). Em escala comercial realiza-se a propagação via seminífera, caracterizada pela elevada heterozigosidade, menor uniformidade dos pomares, frente à variabilidade genética ocasionada por esse método de propagação, acarretando diferentes teores de sólidos solúveis e diferentes cores de suco, prejudicando o aproveitamento industrial do produto (SILVA et al., 2005; ARAUJO et al., 2010).

Portanto, a estaquia ganha destaque como método de propagação alternativo ao de sementes. Segundo Salomão et al. (2002), sua vantagem em relação à enxertia é o menor requerimento de mão-deobra e a possibilidade de clonar tanto variedades-copa como porta-enxertos com características agronômicas desejáveis. De acordo com Silva et al. (2005) e Roncatto et al. (2008b), características como elevada produtividade, frutos com teores elevados de suco e sólidos solúveis totais podem ser perpetuadas por meio da estaquia de plantas-matrizes. Segundo Fachinello et al. (2005), outra vantagem deste método de multiplicação de plantas frutíferas é a formação de pomares uniformes.

Entretanto, deve-se levar em consideração que o maracujazeiro é uma planta auto-incompatível (BRUCKNER et al., 1995), e por isso, no caso da propagação vegetativa, faz-se necessária a utilização de material de várias plantas, para viabilizar a produção de frutos. Segundo Natale et al. (2004), a produção de mudas constitui-se em uma das etapas mais importantes do sistema produtivo, influenciando diretamente no desempenho da planta. Na implantação de um pomar, a qualidade das mudas torna-se fundamental para garantir a homogeneidade, a rápida formação e o início precoce da produção.

A produção de mudas por estaquia é influenciada principalmente: pela aptidão da planta em emitir raízes adventícias, condições favoráveis do ambiente de cultivo como temperatura, umidade, arejamento, luz, ausência de contaminação fúngica ou bacteriana no meio enraizante, composição do substrato, genótipo, recipiente, estádio fisiológico da planta matriz, época de retirada das estacas (OLIVEIRA, 2000; LIMA et al., 2005; BRAGA, et al., 2006; RONCATTO et al., 2008b).

Neste contexto, destaca-se a importância da utilização de substratos apropriados e auxinas para o enraizamento de estacas de maracujazeiro (OLIVEIRA et al., 2002; SOUZA; CARNIEL; FOCHESATO, 2006; VAZ et al., 2009). Existem diversos trabalhos na literatura científica que descrevem a utilização de hormônios sintéticos no enraizamento de estacas de Passifloráceas (JUNQUEIRA et al., 2002; PIRES, 2007; VAZ et al., 2009), contudo são poucos os estudos voltados para a produção de extratos alternativos para este fim.

Uma espécie que tem sido utilizada para a confecção de extratos naturais é a tiririca (Cyperus rotundus). Essa espécie possui sistema reprodutivo altamente eficiente, composto por rizomas, bulbos basais e tubérculos (JAKELAITIS et al., 2003). Segundo Quayyum et al. (2000), tubérculos de $C$. rotundus possuem substâncias inibitórias para algumas plantas cultivadas, contudo existem relatos que afirmam que essas substâncias também podem ser utilizadas para indução de rizogênese em estacas, atuando como sinergistas do ácido indol acético (AIA).

Alguns autores já testaram extratos desta Cyperaceae na rizogênese de estacas de videira (SOZIM et al., 2008), pingo-de-ouro (FANTI, 2008), sapotizeiro (ARRUDA et al., 2009), mandioca (MAHMOUD 
et al., 2009), canela (XAVIER et al., 2009), erva-baleeira (RODRIGUES et al., 2010).

Fanti (2008) estudou o efeito da aplicação de extratos de folhas, tubérculos de C. rotundus e auxinas sintéticas (ANA e AIB) na estaquia caulinar de Duranta repens e observou que a variável número de raízes estaca ${ }^{-1}$ e porcentagem de enraizamento não diferiram significativamente entre os compostos utilizados para induzir a rizogênese. Mahmoud et al. (2009), observaram melhor desenvolvimento de estacas de Manihot esculenta Crantz tratadas com a auxina natural extraída do tubérculo da tiririca do que com o regulador AIB.

Diante do exposto, este trabalho objetivou avaliar o efeito do extrato hidroalcóolico de bulbos basais e tubérculos de $C$. rotundus e de dois substratos na rizogênese de estacas de maracujazeiro amarelo.

\section{MATERIAL E MÉTODOS}

O experimento foi conduzido no Centro de Ciências Agrárias da UFES (CCA-UFES), Alegre - ES (localizado a latitude $20^{\circ} 45^{\prime} \mathrm{S}$ e $41^{\circ} 29^{\prime} \mathrm{W}$ a $270 \mathrm{~m}$ de altitude), no período de setembro a novembro de 2011. Foram utilizados dois substratos, $S_{1}$ : Substrato comercial, composto de turfa vegetal, casca de pinus compostada e vermiculita, umidade de até $50 \%$, densidade de $450 \mathrm{~kg} / \mathrm{m}^{3}, \mathrm{pH}$ em água de $5,7( \pm 0,5)$ e condutividade elétrica de $1,8( \pm 0,3) \mathrm{mS} / \mathrm{cm}$. $\mathrm{S}_{2}$ : vermiculita expandida.

Para a confecção dos extratos de $C$. rotundus foram coletados tubérculos e bulbos basais nas proximidades do Laboratório de Sementes do Centro de Ciências Agrárias da UFES, os quais foram lavados em água corrente, secos com papel toalha, pesados e triturados em liquidificador industrial. Foram utilizados 33,33g de tubérculos ou bulbos basais para $500 \mathrm{~mL}$ de solução hidroalcóolica ( $480 \mathrm{~mL}$ de água deionizada $+20 \mathrm{~mL}$ de álcool hidratado $96^{\circ} \mathrm{GL}$ ). Após serem processados, os extratos de bulbo basal (EB) e de tubérculo (ET) foram peneirados e diluídos em água deionizada nas concentrações: $50 \%$, 75\% e $100 \%$. Ambos os extratos foram preparados no mesmo dia do tratamento das estacas, sendo mantidos em geladeira até sua utilização.

As estacas foram preparadas a partir de ramos do último surto de crescimento de plantas matrizes de Passiflora edulis Sims f. flavicarpa, cultivadas em condições de sequeiro com cerca de dois anos de idade, provenientes do pomar estabelecido na área experimental do CCA-UFES. Os ramos foram seccionados originando estacas com comprimento de 10 a 15 centímetros contendo duas gemas, executando um corte em bisel na extremidade basal e um corte perpendicular na parte apical da estaca, preservando a folha do nó apical cortada ao meio, transversalmente. Em seguida, as estacas foram colocadas em recipiente com água, a fim de evitar a desidratação. Antes das estacas serem imersas por 1 minuto nos extratos, a extremidade basal de cada uma foi seccionada em $0,5 \mathrm{~cm}$. Logo após, as estacas foram acondicionadas em tubetes de $170 \mathrm{~cm}^{3}$ e conduzidas até a câmara de nebulização intermitente sob tela sombrite (50\% de luminosidade). O sistema de irrigação empregado foi o de microaspersão. $\mathrm{O}$ período de aspersão foi de 30 segundos, em intervalos de 5 minutos.

Os tratamentos consistiram de T1: $\mathrm{S}_{1}+\mathrm{H}_{2} \mathrm{O}$ deionizada; T2: $\mathrm{S}_{1}+\mathrm{EB}$ 50\%; T3: $\mathrm{S}_{1}+\mathrm{EB}$ 75\%; T4: $\mathrm{S}_{1}+$ EB 100\%; T5: $\mathrm{S}_{1}+$ ET 50\%; T6: $\mathrm{S}_{1}+$ ET 75\%; T7: $\mathrm{S}_{1}+$ ET 100\%; T8: $\mathrm{S}_{2}+\mathrm{H}_{2} \mathrm{O}$ deionizada; T9: $\mathrm{S}_{2}+$ EB 50\%; T10: $S_{2}+$ EB 75\%; T11: $S_{2}+$ EB 100\%; T12: $S_{2}+$ ET 50\%; T13: $S_{2}+$ ET 75\%; T14: $S_{2}+$ ET $100 \%$.

O tempo de permanência na câmara de nebulização foi de 45 dias, quando foram avaliados os parâmetros: porcentagem de estacas enraizadas (número de estacas que emitiram pelo menos uma raiz com $0,2 \mathrm{~cm})$; número de raízes estaca ${ }^{-1}$; comprimento da maior raiz $(\mathrm{cm})$, massa fresca $(\mathrm{MF})$ e seca das raízes (MS).

Os fatores em estudo foram: dois tipos de substrato $\left(\mathrm{S}_{1}\right.$ e $\left.\mathrm{S}_{2}\right)$, dois extratos de $C$. rotundus (EB e 
ET) e três concentrações $(50,75$ e $100 \%)$ acrescido de 2 testemunhas, no delineamento inteiramente ao acaso em esquema fatorial $[(2 \times 2 \times 3)+2]$ com quatro repetições e três estacas por repetição, resultando em 14 tratamentos. Os dados foram submetidos à análise de variância e as médias comparadas pelo teste de Tukey $(\mathrm{P} \leq 0,05)$, com auxílio do programa estatístico Assistat.

\section{RESULTADOS E DISCUSSÃO}

Os resultados da análise de variância para as variáveis em estudo podem ser observados na Tabela 1.

Tabela 1. Análise de variância para massa fresca (MF) e massa seca da raiz (MS), comprimento da maior raiz (CR), número de raízes (NR) e porcentagem de enraizamento (PE) de estacas de maracujazeiro amarelo (Passiflora edulis f. flavicarpa) cultivadas em dois substratos e submetidas a diferentes concentrações de extrato hidroalcoolico de bulbo basal e tubérculo de Cyperus rotundus. CCA-UFES, Alegre - ES, 2011.

\begin{tabular}{ccccccc}
\hline \multirow{2}{*}{ FV } & \multicolumn{6}{c}{ VARIÁAEIS (TESTE F) } \\
\cline { 2 - 7 } & GL & MF & MS & CR & NR & PE \\
\hline SUBS & 1 & $119,22^{* *}$ & $65,43^{* *}$ & $72,93^{* *}$ & $0,16^{\text {ns }}$ & $1,41^{\text {ns }}$ \\
EXT & 6 & $2,744^{*}$ & $2,09^{\text {ns }}$ & $2,14^{\mathrm{ns}}$ & $2,39^{*}$ & $1,85^{\mathrm{ns}}$ \\
SUBSxEXT & 6 & $0,98^{\mathrm{ns}}$ & $0,77^{\mathrm{ns}}$ & $1,35^{\mathrm{ns}}$ & $2,05^{\mathrm{ns}}$ & $1,20^{\mathrm{ns}}$ \\
\hline RES & 42 & -- & -- & -- & -- & -- \\
\hline MÉDIA GERAL & & 1,41 & 0,11 & 9,40 & 14,96 & 91,66 \\
\hline CV (\%) & & 41,09 & 50,17 & 22,91 & 40,71 & 16,35 \\
\hline Significativo ao nível de 5\% de probabilidade, ${ }^{* *}$ Significativo ao nível de $1 \%$ & de probabilidade, ${ }^{\text {ns }}$ nã
\end{tabular}
significativo.

Não foi observado efeito significativo da interação substrato x extrato para nenhuma variável avaliada. Ao analisar isoladamente o fator substrato observou-se diferença significativa para as variáveis massa fresca (MF), massa seca (MS) e comprimento da maior raiz (CR), contudo para número de raízes (NR) e porcentagem de enraizamento (PE) não houve significância. Para a análise isolada do fator extratos, apenas para MF e NR foi obtida diferença significativa entre as médias, enquanto as variáveis MS, CR e PE apresentaram médias semelhantes estatisticamente.

Na Tabela 2 estão contidos os valores médios de MF, MS, CR, NR e PE. A análise isolada do fator substratos indicou diferença significativa entre os substratos para as três primeiras variáveis, sendo o substrato comercial $\left(S_{1}\right)$ o que apresentou as maiores médias. Não houve diferença estatística entre os substratos quando se comparou as médias de NR e PE.

Tabela 2. Valores médios da massa fresca da raiz (MF), massa seca da raiz (MS), comprimento da maior raiz (CR), número de raízes (NR) e porcentagem de enraizamento (PE) de estacas de maracujazeiro amarelo (Passiflora edulis f. flavicarpa) cultivadas em diferentes substratos. CCAUFES, Alegre - ES, 2011.

\begin{tabular}{cccccc}
\hline Substrato & MF $(\mathrm{g})$ & MS $(\mathrm{g})$ & $\mathrm{CR}(\mathrm{cm})$ & $\mathrm{NR}$ & PE \\
\cline { 2 - 6 } $\mathrm{S}_{1}$ & $2,25 \mathrm{a}$ & $0,17 \mathrm{a}$ & $11,85 \mathrm{a}$ & $15,29^{\mathrm{ns}}$ & $94,05^{\mathrm{ns}}$ \\
$\mathrm{S}_{2}$ & $0,56 \mathrm{~b}$ & $0,05 \mathrm{~b}$ & $6,94 \mathrm{~b}$ & $14,63^{\mathrm{ns}}$ & $89,28^{\mathrm{ns}}$ \\
\hline DMS & 0,31 & 0,03 & 1,16 & 3,29 & 8,09
\end{tabular}

Médias seguidas da mesma letra minúscula na coluna não diferem entre si pelo teste de Tukey a $1 \%$ de probabilidade. ${ }^{\text {ns }}$ não significativo. $S_{1}-$ Substrato comercial; $S_{2}-$ Vermiculita.

Nucleus, v.9, n.2, out.2012 
Vários fatores podem influenciar o enraizamento de estacas, tanto os intrínsecos, relacionados à própria planta, como os extrínsecos, relacionado às condições ambientais. Os principais fatores internos são os fitormônios (principalmente auxinas), e os externos são luz, temperatura e umidade; que tanto podem agir durante o enraizamento, como também no condicionamento da planta-matriz (RODRIGUES, 1996; NORBERTO et al., 2001). Esses fatores, associados à boa qualidade do substrato devem ser levados em consideração na propagação vegetativa do maracujazeiro (RUGGIERO, 1987), visto que o substrato é um insumo essencial para o sucesso desta técnica.

Os resultados obtidos no presente estudo, comparando os tipos de substrato para produção de mudas de maracujazeiro amarelo via estaquia corroboram com os encontrados por Silva, Peixoto e Junqueira (2001), no qual os autores verificaram que o substrato comercial utilizado para produção de mudas desta mesma espécie (via seminífera) proporcionou valores mais elevados que a vermiculita para todas as características analisadas (altura, diâmetro, massa seca da parte aérea e raiz). Possivelmente, isto se deve à composição química do $S_{1}$, que possui teores mais elevados de nutrientes contidos na matéria orgânica (composto de turfa vegetal e casca de pinus compostada).

Salomão et al. (2002), obtiveram médias de comprimento da maior raiz de 12,3 e 5,3 cm para maracujazeiro doce e amarelo, respectivamente. Este autor e seus colaboradores utilizaram como substrato casca de arroz carbonizada e o resultado obtido para o maracujazeiro amarelo foi próximo ao obtido no presente estudo para a vermiculita expandida $\left(S_{2}\right)$, que apresentou média de $6,94 \mathrm{~cm}$ para a variável CR. Contudo, o $\mathrm{S}_{1}$ propiciou melhores condições para o desenvolvimento radicular, alcançando média de $11,85 \mathrm{~cm}$, além de maior produção de MF (1,64 g) e MS (1,01 g).

Souza et al. (2006), avaliando diferentes proporções de vermiculita (V) e casca de arroz carbonizada (CAC) na estaquia de maracujazeiro amarelo, verificou que a melhor resposta de enraizamento foi obtida pelo substrato formado pelas misturas dos dois componentes, nas proporções de 50\% V: $50 \%$ CAC e 25\% V: 75\% CAC. Este autor e seus colaboradores inferiram que a quantidade de água aplicada às diversas misturas foi prejudicial à vermiculita isoladamente por ter, provavelmente, retido água em demasia, causando deficiência de oxigênio no substrato. Possivelmente este fato tenha ocorrido no presente estudo, prejudicando o desenvolvimento radicular das estacas cultivadas neste substrato.

As médias de PE encontradas neste trabalho, 94,5 e 89,28\% no $S_{1}$ e $S_{2}$, respectivamente, corroboram com as de outros autores que, estudando a mesma espécie, obtiveram 90\% (SÃO JOSÉ et al., 1994) e 96\% (SALOMÃO et al., 2002). Contudo, existem resultados inferiores aos obtidos neste trabalho, como os encontrados por Oliveira et al. (2002), com enraizamento variando de 20,7 a 74,0 \% utilizando diferentes substratos e por Roncatto et al. (2008a), que alcançou 76,7\% de enraizamento de estacas desta mesma espécie utilizando vermiculita de textura média.

Apesar de ambos os substratos utilizados neste trabalho apresentarem médias elevadas de PE (superior a $80 \%$ ) os maiores valores de MF, MS e CR foram obtidos no substrato comercial $\left(\mathrm{S}_{1}\right)$, indicando a possibilidade de produção de mudas mais vigorosas neste meio enraizante. O sistema radicular menos desenvolvido, como observado no $\mathrm{S}_{2}$, pode trazer problemas no desenvolvimento das mudas quando transplantadas.

Uma das possíveis causas para essa variação na porcentagem de enraizamento pode estar relacionada a determinados fatores como época do ano que foi realizada a retirada das estacas. Segundo Almeida et al. (1991), a primavera é a época favorável para o enraizamento de estacas de maracujazeiro amarelo, conseguindo resultado superior a $90 \%$ de enraizamento. Nesta mesma época Roncatto et al. (2008a) obtiveram 76,7\% enraizamento e Roncatto et al. (2008b) verificaram que a espécie $P$. edulis f. 
flavicarpa mostrou dificuldade em enraizar no verão (23,33\% enraizamento). Oliveira et al. (2002) observaram $75 \%$ de enraizamento por dois anos consecutivos no mês de agosto.

Outro fator que pode estar relacionado aos resultados divergentes de PE encontrados na literatura científica é posição do ramo onde foi realizada a coleta das estacas. Salomão et al. (2002) utilizando estacas de ramos de maracujazeiro amarelo das regiões apical, mediana e basal, obteve porcentagens de enraizamento de 69\% para estacas coletadas na região apical e $96 \%$ para as regiões mediana e basal. Segundo estes autores, a PE obtida nas estacas da posição apical foi significativamente menor em comparação com a obtida nas outras duas.

A Tabela 3 apresenta os valores médios de MF, MS, CR, NR e PE em função dos extratos. Para a variável MF e NR todas as médias observadas foram semelhantes estatisticamente entre si, sendo que os valores de MF variaram de 1,09 a 1,93 g e o NR variou de 11,39 a 20,66. Os dados de MS, CR e PE não apresentaram diferença significativa entre os diferentes extratos (Tabela 3). É importante destacar que foi possível obter 100\% de enraizamento, média de CR de 11,57 e 16,62 para NR nas estacas tratadas apenas com água deionizada.

Tabela 3. Massa fresca da raiz (MF), massa seca da raiz (MF) comprimento da maior raiz (CR), número de raízes (NR) e porcentagem de enraizamento (PE) de estacas de maracujazeiro amarelo (Passiflora edulis f. flavicarpa) submetidas a diferentes extratos hidroalcoólicos de bulbo basal (EB) e de tubérculo (ET) de C. rotundus. CCA-UFES, Alegre - ES, 2011.

\begin{tabular}{cccccc}
\hline Extratos & MF $(\mathrm{g})$ & MS $(\mathrm{g})$ & $\mathrm{CR}(\mathrm{cm})$ & $\mathrm{NR}$ & PE \\
\cline { 2 - 6 } 1 & $1,93 \mathrm{a}$ & $0,16^{\mathrm{ns}}$ & $11,57^{\mathrm{ns}}$ & $16,62 \mathrm{a}$ & $100,00^{\mathrm{ns}}$ \\
2 & $1,09 \mathrm{a}$ & $0,09^{\mathrm{ns}}$ & $8,41^{\mathrm{ns}}$ & $12,87 \mathrm{a}$ & $91,67^{\mathrm{ns}}$ \\
3 & $1,28 \mathrm{a}$ & $0,11^{\mathrm{ns}}$ & $8,88^{\mathrm{ns}}$ & $13,82 \mathrm{a}$ & $95,83^{\mathrm{ns}}$ \\
4 & $1,32 \mathrm{a}$ & $0,10^{\mathrm{ns}}$ & $8,88^{\mathrm{ns}}$ & $17,20 \mathrm{a}$ & $83,33^{\mathrm{ns}}$ \\
5 & $1,84 \mathrm{a}$ & $0,15^{\mathrm{ns}}$ & $10,23^{\mathrm{ns}}$ & $20,66 \mathrm{a}$ & $100,00^{\mathrm{ns}}$ \\
6 & $1,21 \mathrm{a}$ & $0,09^{\mathrm{ns}}$ & $8,85^{\mathrm{ns}}$ & $11,39 \mathrm{a}$ & $87,50^{\mathrm{ns}}$ \\
7 & $1,16 \mathrm{a}$ & $0,09^{\mathrm{ns}}$ & $8,94^{\mathrm{ns}}$ & $12,16 \mathrm{a}$ & $83,33^{\mathrm{ns}}$ \\
\hline DMS & 0,89 & 0,09 & 3,33 & 9,43 & 23,21 \\
\hline
\end{tabular}

Médias seguidas da mesma letra minúscula na coluna não diferem entre si pelo teste de Tukey a $5 \%$ de probabilidade. ${ }^{\text {ns }}$ não significativo. 1) $\mathrm{H}_{2} \mathrm{O}$ deionizada; 2) EB 50\%; 3) EB 75\%; 4) EB 100\%; 5) ET 50\%; 6) ET 75\%; 7) ET $100 \%$.

Condições internas da planta como o balanço hormonal entre inibidores, promotores e co-fatores de enraizamento interfere no crescimento das raízes (SANTOS, 1994). Quando o balanço hormonal entre promotores e inibidores é favorável aos promotores, ocorre o processo de iniciação radicular. Uma das formas mais comuns de favorecer o balanço hormonal é a aplicação exógena de reguladores vegetais, elevando o teor de auxinas no tecido (PASQUAL et al., 2001).

Como observado neste trabalho o maracujazeiro amarelo não requer aplicação de compostos com efeito auxínico para induzir a rizogênese. Segundo a classificação descrita por Hartmann et al. (2002), o qual organiza os principais grupos vegetais quanto ao enraizamento, as plantas que possuem em seus tecidos substâncias endógenas necessárias à iniciação radicial e não exigem a aplicação de qualquer substância exógena para que as estacas formem raízes são classificadas como plantas de fácil enraizamento. A partir dos dados obtidos no presente estudo e encontrados na literatura científica é possível inferir que, além do maracujazeiro amarelo, outras espécies da família Passifloraceae, como Passiflora cincinnata Mast. (ARAUJO et al., 2010), Passiflora serrato-digitata (BRAGA et al., 2006) e Passiflora actinia (KOCH et al., 2001) sejam classificadas como plantas de fácil enraizamento. 
Araujo et al. (2010), trabalhando com maracujá-do-mato concluiu que esta espécie pode ser propagada por estacas sem a utilização do AIB em substrato composto da mistura de solo + fibra de coco + húmus de minhoca. Braga et al. (2006), em experimento conduzido com três espécies silvestres, sem utilizar regulador de crescimento, obteve maior sucesso na formação de mudas com a espécie $P$. serratodigitata que apresentou 94,3\% das estacas transformadas em mudas (enraizadas e com brotos). Koch et al. (2001) obtiveram média de $90 \%$ de enraizamento em P. actinia, concluindo que não haveria necessidade de uso de reguladores para o enraizamento de estacas semilenhosas dessa espécie. Salomão et al. (2002), obteve porcentagem de enraizamento superior a $90 \%$ em maracujazeiro doce e amarelo sem utilização de regulador vegetal. Portanto, a propagação por estaquia destas espécies dispensa o uso desse insumo, reduz o custo final da muda e beneficia tanto viveiristas como fruticultores.

Além do fato das estacas possivelmente possuírem conteúdos endógenos suficientes de substâncias capazes de estimularem o enraizamento, a presença de folhas nos segmentos propagados possivelmente tenha favorecido a produção de auxina. No presente estudo metade de uma folha foi mantida no ápice de cada estaca. Segundo Woodward e Bartel (2005), auxinas são produzidas principalmente nos meristemas apicais, mas também podem ser produzidas nas folhas. Além da produção de auxinas, as folhas também produzem carboidratos, que são importantes para o desenvolvimento das raízes. Desta forma, mantendo-se as folhas, não seria necessária a aplicação de auxinas (BRAGA et al., 2006). Segundo Meletti e Nagai (1992), a permanência de folhas nas estacas é determinante no enraizamento de algumas espécies de passiflora.

É provável que a baixa concentração dos extratos de tubérculo e bulbo basal de $C$. rotundus utilizados não tenha promovido acentuado desbalanceamento interno das substâncias responsáveis pela emissão e crescimento das raízes. Assim, não houve uma alteração a ponto de intensificar ou reduzir a rizogênese e gerar diferença significativa entre os extratos utilizados para as variáveis analisadas. Visto que Arruda et al. (2009) utilizaram extrato de tubérculos de tiririca no enraizamento de estacas de sapotizeiro e observaram que as estacas mostraram uma relação dose-dependente, ou seja, a medida que houve um aumento na concentração do extrato, aumentou a sobrevivência e o enraizamento das estacas de sapotizeiro.

Estudos realizados por Meguro (1969) confirmaram a presença de ácido indol acético (IAA) nos tubérculos de C. rotundus. Este fitormônio pode apresentar efeito sinergístico, ou seja, estimular o efeito do IAA, quando aplicados em concentrações ótimas, pois concentrações muito altas poderiam provocar toxidez às plantas e assim, inibir o efeito auxínico.

Mahmoud et al. (2009) testaram o efeito da auxina natural extraída do tubérculo da tiririca, AIB e de um fertilizante a base de nitrogênio e zinco, na formação de raízes e brotos de mandioca. $\mathrm{O}$ autor e seus colaboradores concluíram que o extrato do tubérculo de tiririca possui ação fitormônica, promovendo a maior média individual de brotos e maior média geral de raízes e brotos nas manivas na primeira fase de brotação das estacas de mandioca.

Fanti (2008) estudou a estaquia de pingo-de-ouro (Duranta repens L.), um arbusto utilizado em jardinagem. Este autor utilizou extratos de folhas e de tubérculos de tiririca comparando sua ação à de auxinas sintéticas (ANA e AIB) e observou que a aplicação dos extratos de folhas e de tubérculos de tiririca não apresentou diferença estatística dos reguladores vegetais utilizados no enraizamento dessa espécie em diferentes épocas. O mesmo autor obteve porcentagem de enraizamento estatisticamente igual para todos os tratamentos, resultado semelhante ao encontrado no presente trabalho.

Rodrigues et al. (2010) utilizando extrato oriundo de um macerado de folhas e tubérculos de tiririca não observou diferença estatisticamente significativa entre os tratamentos avaliados, indicando que, independente da concentração, o extrato de tiririca não alterou o enraizamento de estacas de erva-

Nucleus, v.9, n.2, out.2012 
baleeira. Este autor e seus colaboradores também obtiveram enraizamento em estacas tratadas apenas com água destilada.

A partir dos resultados do presente estudo sugere-se que outros testes sejam realizados com extratos de bulbo basal de $C$. rotundus a fim de obter resultados mais conclusivos acerca da existência de substâncias inibidoras do enraizamento ou de efeito auxínico em sua composição química.

\section{CONCLUSÃO}

De acordo com os resultados obtidos e nas condições em que o presente trabalho foi realizado, pode-se concluir que o substrato comercial $\left(S_{1}\right)$ favorece o desenvolvimento radicular das estacas, sendo o mais recomendado para propagação vegetativa do maracujazeiro amarelo.

As concentrações do extrato hidroalcóolico de bulbo basal e tubérculo de $C$. rotundus utilizadas não influenciam o enraizamento de estacas de maracujazeiro amarelo.

\section{AGRADECIMENTOS}

Agradecimento a CAPES, pela concessão de bolsa de estudo ao primeiro autor.

\section{REFERÊNCIAS}

ALMEIDA, L. P. de; BOARETTO, M.A.C.; SANTANA, R.G. de. Estaquia e comportamento de maracujazeiros (Passiflora edulis Sims f. flavicarpa Degener) propagados por via sexual e vegetativa. Revista Brasileira de Fruticultura, Jaboticabal, v.13, n.1, p.157-159, 1991.

ARAUJO, F. P.et al. Substratos e concentrações de ácido indolibutírico no enraizamento de estacas de Passiflora cincinnata Mast. Magistra, Cruz das Almas - BA, v. 22, n. 1, p. 21-27, 2010.

ARRUDA, L. A. M.et al. Atividade hormonal do extrato de tiririca na rizogênese de estacas de sapoti. In: Jornada de Ensino, Pesquisa e Extensão e Semana Nacional de Ciência e Tecnologia, 9. Anais... Recife: Universidade Federal Rural de Pernambuco, v.9. 2009.

BRAGA, M. F.et al. Enraizamento de estacas de três espécies silvestres de Passiflora. Revista Brasileira de Fruticultura, Jaboticabal, v. 28, n. 2, p. 284-288, 2006.

BRUCKNER, C.H.et al. Self-incompatibility in passion fruit (Pasiflora edulis Sims). Acta Horticulturae, Wageningen, n. 370, p. 45-57, 1995.

FACHINELLO, J. C. et al. Propagação vegetativa por estaquia. In: FACHINELLO, J.; HOFFMANN, A.; NACHTIGAL, J.C. (Eds.). Propagação de plantas frutíferas. Brasília: Embrapa Informação Tecnológica, 2005. 221p.

FANTI. F. P. Aplicação de extratos de folhas e de tubérculos de Cyperus rotundus L. (Cyperaceae) e de auxinas sintéticas na estaquia caulinar de Duranta repens L. (Verbenaceae). 2008. 69 f. Dissertação (Mestrado em Botânica). Universidade Federal do Paraná.

HARTMANN, H. T. et al. Plant propagation: principles and practices. New Jersey: Prentice-Hall, 2002. $880 \mathrm{p}$.

IBGE. Instituto Brasileiro de Geografia e Estatística. Produção Agrícola Municipal, 2009. Disponível em: <http:// www.sidra.ibge.gov.br >. Acesso em: 04 out. 2011. 
JAKELAITIS, A. FERREIRA et al.. Efeitos de sistemas de manejo sobre a população de tiririca. Planta Daninha, Viçosa, v.21, n.1, p. 89-95, 2003.

JUNQUEIRA, N. T. V.et al. Propagação do maracujazeiro-azedo por enxertia em estacas herbáceas enraizadas de espécies de passifloras nativas. Planaltina: Embrapa Cerrados, 2002. 15p. (Boletim de Pesquisa e Desenvolvimento, 39).

KOCH, R. C.et al. Vegetative propagation of Passiflora actinia by semihardwood cuttings. Semina: Ciências Agrárias, Londrina, v. 22, n. 2, p. 165-167, 2001.

LIMA, R. L. S.et al. Enraizamento de estacas caulinares de acerola em função da composição do substrato. Semina: Ciências Agrárias, Londrina, v. 26, n. 1, p. 27-32, 2005.

MAHMOUD, T. S.et al. Avaliação do efeito de hormônio natural, sintético e indutor no desenvolvimento da primeira fase de brotação das estacas de Manihot esculenta Crantz. CONGRESSO BRASILEIRO DE MANDIOCA, 13. Botucatu. Revista Raízes e Amidos Tropicais. Botucatu: CERAT/UNESP. 2009. p. 621-625.

MEGURO, M. Substâncias reguladoras de crescimento em rizoma de Cyperus rotundus L. Boletim de Botânica. São Paulo. Faculdade de Filosofia, Ciências e Letras, Universidade de São Paulo, n. 33, p. 147$171,1969$.

MELETTI, L. M. M.; NAGAI, V. Enraizamento de estacas de sete espécies de maracujazeiro (Passiflora spp). Revista Brasileira de Fruticultura, Cruz das Almas, v.14, n. 2, p. 163-168, 1992.

NATALE, W.et al. Efeitos da aplicação de zinco no desenvolvimento, no estado nutricional e na produção de matéria seca de mudas de maracujazeiro. Revista Brasileira de Fruticultura, v.26, p. 310-314, 2004.

NOGUEIRA FILHO, G. C.et al. Produção de mudas de maracujazeiro-amarelo por enxertia hipocotiledonar sobre sete espécies de passiflora. Revista Brasileira de Fruticultura, Jaboticabal, v.33, n.1, p. 237-245, 2011.

NORBERTO, P. M.et al. Efeito da época de estaquia e do AIB no enraizamento de estacas de figueira (Ficus carica L.). Ciência e Agrotecnologia, Lavras, v. 25, n. 3, p. 533-541, 2001.

OLIVEIRA, J. A. Efeito dos substratos artificiais no enraizamento e no desenvolvimento de maracujá-azedo e doce por estaquia. 2000. 71 f. Dissertação (Metrado em Agronomia) - Faculdade de Agronomia e Medicina Veterinária, Universidade de Brasília.

OLIVEIRA, J. A.et al. Efeito dos substratos artificiais no enraizamento e no desenvolvimento de estacas de maracujazeiro-azedo (Passiflora edulis Sims f. flavicarpa Deg.). Revista Brasileira de Fruticultura, Jaboticabal, v.24, n.2, p.505-508, 2002.

PASQUAL, M. et al. Fruticultura comercial: propagação de plantas frutíferas. Lavras: UFLA/FAEPE, 2001. $137 \mathrm{p}$.

PIRES, M. C. Propagação de maracujazeiro por estaquia e enxertia em estacas enraizadas. mar. 2007. 86 f. Dissertação (Mestrado em Ciências Agrárias) - Universidade de Brasília.

QUAYYUM, H. A. et al. Growth inhibitory effects of nutgrass (Cyperus rotundus) on rice (Oryza sativa) seedlings. Journal of Chemical Ecology, New York, v. 26, n. 9, p. 2221-2231, 2000.

RODRIGUES, A. K. C.et al. Enraizamento de estacas de Cordia verbenacea DC. tratadas com Cyperus rotundus L.. In: Seminário de Agroecologia de Mato Grosso do Sul, 3. Anais... Corumbá: Embrapa CPAP, 2010. p.1-5. 
RODRIGUES, G. C. Aspectos fisiológicos da propagação de fruteiras. In: PINTO, A.C.Q. (Coord.). Produção de mudas frutíferas sob condições do ecossistema de Cerrados. Planaltina: Embrapa-CPAC, 1996. p. 29-33. (Documentos, 62).

RONCATTO, G.et al. Enraizamento de estacas herbáceas de diferentes espécies de maracujazeiro.

Revista Brasileira de Fruticultura, Jaboticabal, v. 30, n. 4, p. 1094-1099, 2008 a.

RONCATTO, G. et al. Enraizamento de estacas de espécies de maracujazeiro (Passiflora spp.) no inverno e no verão. Revista Brasileira de Fruticultura, Jaboticabal, v. 30, n. 4, p.1089-1093, 2008 b.

RUGGIERO, C. (Ed.). Maracujá. Jaboticabal: UNESP-FCAV, 1987. 250 p.

SALOMÃO, L. C. C.et al. Propagação por estaquia dos maracujazeiros doce (Passiflora alata Dryand.) e amarelo (P. edulis f. flavicarpa Deg.). Revista Brasileira de Fruticultura, Jaboticabal, v.24, n.1, p.163$167,2002$.

SANTOS, S. C. Efeitos de épocas de poda sobre a produção e qualidade dos frutos da figueira (Ficus carica L.), cultivada em Selvíria-MS. 1994. 50 f. Dissertação (Mestrado em Agronomia) - Universidade Estadual de São Paulo, Ilha Solteira.

SÃO JOSÉ, A. R. et al. Formação de mudas de maracujazeiro. In: SÃO JOSÉ, A. R. (Ed.). Maracujá: produção e mercado. Vitória da Conquista: UESB, 1994. p. 41-47.

SILVA, F. M.et al. Enxertia de mesa de Passiflora edulis Sims f. flavicarpa Deg. sobre Passiflora alata Curtis. Revista Brasileira de Fruticultura, Jaboticabal, v. 27, n.1, p.98 - 101, 2005.

SILVA, R. P.; PEIXOTO, J. R.; JUNQUEIRA, N. T. V. Influência de diversos substratos no desenvolvimento de mudas de maracujazeiro azedo (Passiflora edulis Sims f. flavicarpa DEG). Revista Brasileira de Fruticultura, Jaboticabal, v.23, n.2, p.377-381, 2001.

SOUZA, P. V. D.; CARNIEL, E.; FOCHESATO, M. L. Efeito da composição do substrato no enraizamento de estacas de maracujazeiro azedo. Revista Brasileira de Fruticultura, Jaboticabal, v. 28, n. 2, p. 276-279, 2006.

SOZIM, M.et al. Enraizamento de estacas de videira (Vitis labrusaca L.) cv. Bordô. In: Congresso Brasileiro de Fruticultura, 20. Anais...Vitória. 2008. CD-ROM.

VAZ, C. F.et al. Enraizamento de espécies silvestres de maracujazeiro utilizando cinco doses de ácido indolilbutírico. Revista Brasileira de Fruticultura, Jaboticabal, v. 31, n. 3, p. 816-822, 2009.

XAVIER, A. S.et al. Indução de enraizamento em canela Cinnamomum zeylanicum Blume através do extrato de tiririca. In: Jornada de Ensino, Pesquisa e Extensão da UFRPE, 9. Anais...Recife: Universidade Federal Rural de Pernambuco, v.9. 2009.

WOODWARD, A.W.; BARTEL, B. Auxin: regulation, action, and interaction. Annals of Botany, London, v. 95, p. 707-735, 2005. 